\title{
Indigo Carmine Dye-Assisted Lymphatic-Sparing Laparoscopic Palomo Varicocelectomy In Children
}

\author{
Hiroki Ishibashi, ${ }^{1,2)}$, Hiroki Mori", Keigo Yada', Mitsuo Shimada), Tomoko Sogami', \\ and Akira $\mathrm{Nii}^{2}$ \\ ${ }^{1)}$ Department of Pediatric Surgery and Pediatric Endoscopic Surgery, Tokushima University Hospital, \\ Tokushima, Japan, ${ }^{2}$ Department of Pediatric Surgery, National Kagawa Children's Hospital, Kagawa, \\ Japan
}

\begin{abstract}
The ideal method for varicocelectomy in children remains controversial. We present our experience with dye-assisted lymphatic-sparing laparoscopic varicocelectomy (LSLV) in children, which overcomes the limitations of previously described techniques. Materials and methods : Five consecutive LSLVs were performed over a period of three years on children with a mean age of twelve years. The varicocele grade was three in one case and grade 2 in four cases, respectively. A left subdartos injection of $2 \mathrm{ml}$ of Indigo carmine dye was done using a 25 -gauge needle at ten minutes before an operation. A scrotal injection of lymphatic dye was utilized to spare at least one lymphatic and the remaining spermatic vessels were divided. Results : Lymphatic-sparing was accomplished in all cases. No peri-operative complication was noted. We spared one lymphatic channel in one patient (20\%) and two channels in four patients (80\%). There were no cases of hydrocele or residual varicocele. Conclusion : Dye-assisted LSLV is easily accomplished with an excellent surgical outcome and sparing one or two lymphatics appears to be sufficient to avoid secondary hydrocele. J. Med. Invest. 61 : 151-155, February, 2014
\end{abstract}

Keywords : Laparoscopic Palomo, Lymphatic sparing, Dye, children

\section{INTRODUCTION}

Varicocele is generally considered to be the most common correctable cause of male infertility (1). Varicocele is a relatively rare disorder in children. Varicocele occurs in $10 \%$ to $15 \%$ of children and adolescents (2). Although uncommon before puberty, the incidence of varicocele in postpubertal children is similar to that of adulthood (3).

Multiple methods exist for the treatment of varicoceles, including spermatic vein sclerotherapy or

Received for publication December 3, 2013 ; accepted January 8,2014 .

Address correspondence and reprint requests to Hiroki Ishibashi, M.D., Department of Pediatric Surgery and Pediatric Endoscopic Surgery, Tokushima University Hospital, Kuramotocho, Tokushima, 770-8503, Japan and Fax : +81-88-631-9698. embolization, open inguinal ligation of the spermatic vein, subinguinal microscopic varicocelectomy, and, most recently, laparoscopy. Classically, varicocelectomy may be performed either as a high retroperitoneal ligation of the spermatic vessels as described by Palomo (4) or as a low superficial inguinal ligation as described by Ivanissevich (5).

Varicocelectomy in children is still without a gold standard method. Though the microscopic low ligation technique appears to be effective in adults, there is a reported risk of testicular loss due to arterial injury. This risk is potentially higher in the hands of less experienced surgeons and if the vessels are smaller as in children. The Palomo method of retroperitoneal mass ligation of the spermatic vessels offers a low recurrence rate but with the risk of postoperative hydrocele in $10 \%$ short term and up to $30 \%$ 
with extended follow-up $(1,2)$. It is suggested that this is due to the interruption of the lymphatic outflow from the subservient testis by mass ligation of the spermatic vessels including the lymphatics (6).

We present our experience with dye-assisted lymphatic sparing laparoscopic Palomo varicocelectomy (LSLV) in children. We contribute novel insights regarding the number of lymphatic vessels which need to be preserved.

\section{MATERIALS AND METHODS}

Between 2009 and 2012, five consecutive left LSLVs were performed at two institutions. Clinical, operative and postoperative data were collected from a retrospective chart review.

Children had a mean age of $12 \pm 0.7$ years (a range of 11 to 13 years) and all had primary varicocele on the left side. Clinical grading was done according to Dubin and Amelar. A grade 3 varicocele was detected in one child while four children had a grade 2 varicocele. Indications of operation were testicular volume asymmetry of greater than $20 \%$ in one patient (a grade 3 varicocele), scrotal pain or discomfort in three patients and family preference in one patient.

All patients had general anesthesia and were placed in the supine position with a slight Trendelenburg position. $2 \mathrm{ml}$ of Indigo carmine dye was injected into the space between the tunica vaginalis and tunica albuginea using a 25-gauge needle at ten minutes before the start of an operation (Fig. 1).

A trans-peritoneal approach was used via a 5$\mathrm{mm}$ umbilical incision. Pneumo-peritoneum was established followed by the placement of two $5 \mathrm{~mm}$ ports at the bilateral lower abdominal quadrants. A small posterior peritoneotomy was done over the spermatic vessels. Stained lymphatics were easily seen running alongside the spermatic artery and vein (Fig. 2a). If the stained lymphatics were not immediately seen after posterior peritoneotomy, the

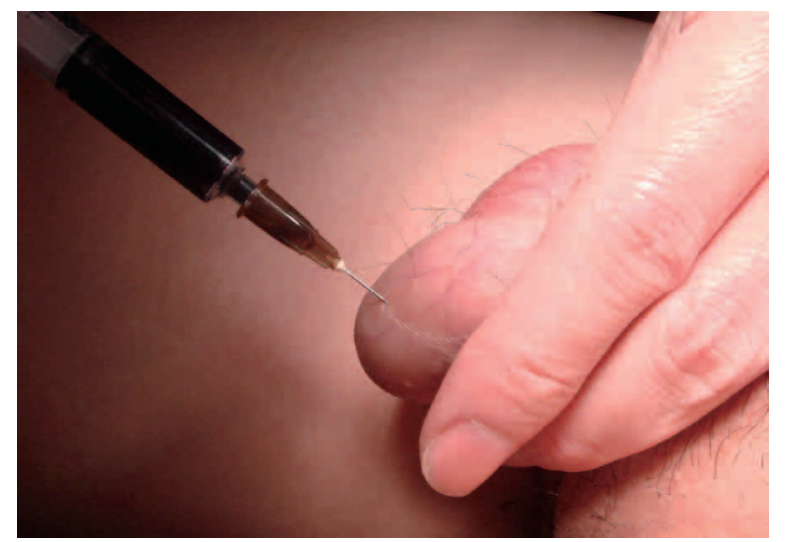

Figure 1 : Dye injection procedure

$2 \mathrm{ml}$ of Indigo carmine dye is injected into the space between the tunica vaginalis and tunica albuginea using a 25 -gauge needle.
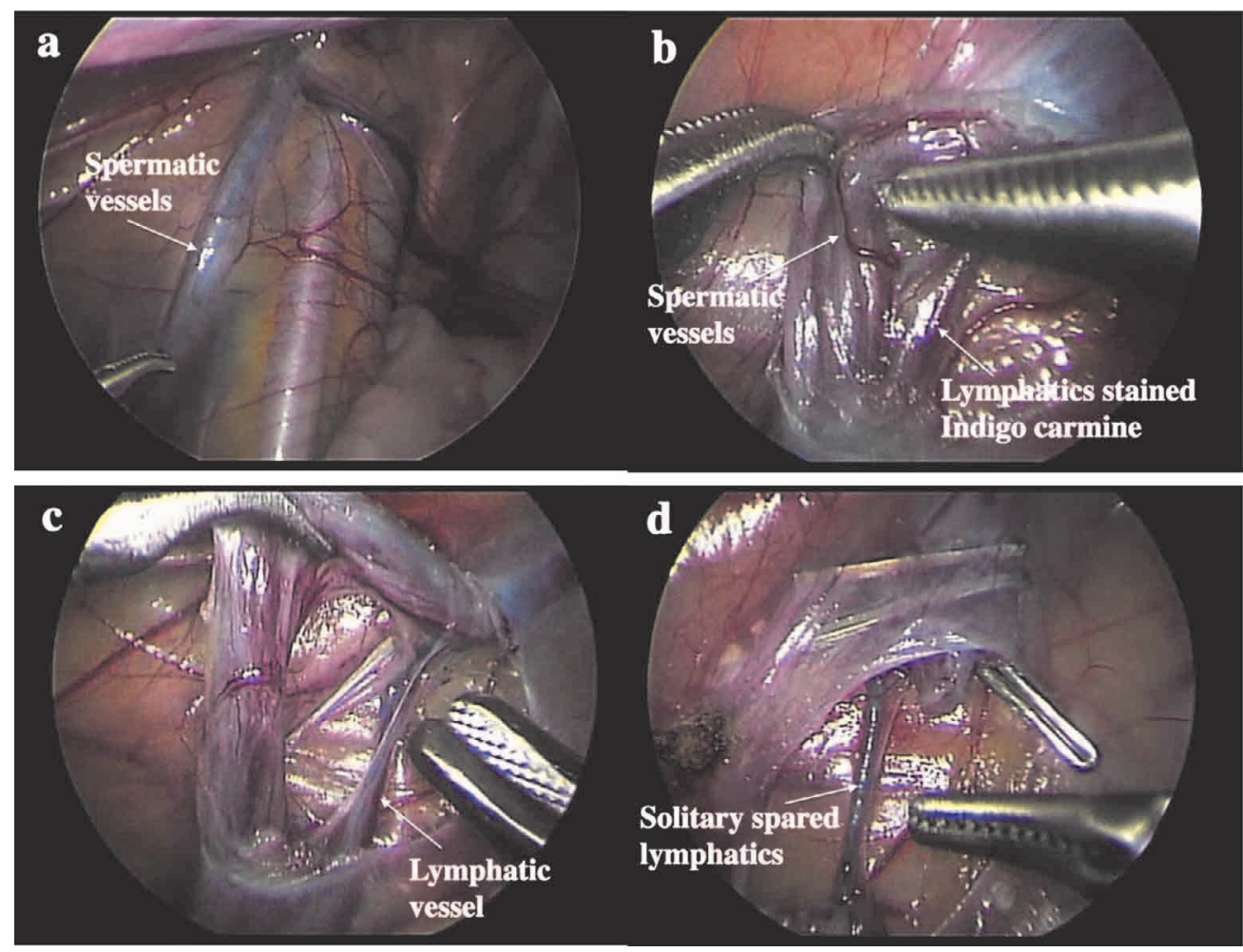

Figure 2 : Laparoscopic procedures

a. b. Lymphatics stained Indigo carmine are easily identified running alongside the spermatic vessels. Intentionally one or two lymphatic is spared.

c. d. Clipping and division of the remaining spermatic vessels. Solitary spared lymphatic is seen after division of the spermatic vessels. 
massage of the scrotum resulted in a good dyeing of lymphatics (Fig. 2b). We intentionally spared one or two lymphatics (Fig. 2c) and the rest of the spermatic vessels were clipped and divided (Fig. 2d). Follow-up was routinely requested on one, six and twelve months, post-operatively.

\section{RESULT}

Dye-assisted LSLV was accomplished successfully in all patients with no intraoperative or postoperative complications. No open conversion was needed. All patients were discharged on the next day following the operation. One injection was all that was required to establish satisfactory lymphangiography in all patients. Table 1 shows summary of cases performed dye-assisted LSLV.

Table 1 : Summary of cases performed dye-assisted lymphatic sparing laparoscopic Palomo varicocelectomy

\begin{tabular}{|c|c|c|c|c|c|c|}
\hline case & age $(\mathrm{Y})$ & side & Grade & $\begin{array}{l}\text { Preserved } \\
\text { lymphatics }\end{array}$ & $\begin{array}{c}\text { Postoperative } \\
\text { hydrocele }\end{array}$ & $\begin{array}{r}\text { Residual } \\
\text { varicocele }\end{array}$ \\
\hline 1 & 11 & left & 3 & 1 & - & - \\
\hline 2 & 13 & left & 2 & 2 & - & - \\
\hline 3 & 12 & left & 2 & 2 & - & - \\
\hline 4 & 12 & left & 2 & 2 & - & - \\
\hline 5 & 12 & left & 2 & 2 & - & - \\
\hline
\end{tabular}

We spared one lymphatic channel in one patient (20\%), two channels in four patients $(80 \%)$. The mean operative time was $95 \pm 26$ minutes (the range from 75 to 130 minutes). One patient underwent ipsilateral laparoscopic hernia repair in the same setting for external inguinal hernia. The mean followup period was 23.3 months (the range from 12 to 38 months). There were no cases of hydrocele and residual varicocele noted. No testicular atrophy was observed at follow-up. Three patients who presented with scrotal pain or discomfort achieved complete resolusion of their symptoms. Catch-up growth couldn't be quantified in one hypotrophy patient with both pre and postoperative ultrasound at a follow-up of 24 months.

\section{DISCUSSION}

The techniques currently utilized for varicocele repair include the standard inguinal approach, the microscopic subinguinal approach, laparoscopic techniques, high retro- peritoneal Palomo procedure and radiological interventional sclerotherapy. However, each technique has advantages and disadvantages and there is no agreement on a gold standard in the pediatric age group. The laparoscopic approach for varicocelectomy was introduced into clinical practice in the early 1990s, and during the last decade, this procedure has gained popularity especially in children because it is a minimally invasive simple and safe technique with a high success rates of $98 \%$, which is similar to that of the microsurgical technique. Even so, many surgeons were still reporting secondary hydrocele rates of $10 \sim 30 \%$ $(1,2)$.

It is suggested that the development of a secondary hydrocele is due to the interruption of the lymphatic outflow from the subservient testis by mass ligation of the spermatic vessels including the lymphatics. Kocvara et al (6) demonstrated interstitial edema and local reduced spermatogenesis with desquamation of the germinal epithelium, atrophy, and Sertoli cell only pattern in up to $16 \%$ of the seminiferous tubules on testicular biopsy after varicocelectomy. They, therefore, concluded that dividing the lymphatic vessels can aggravate testicular function and interfere with the hypothalamic-pituitary-testicular axis. They affirmed that lymphatic sparing is important not only to prevent postoperative hydrocele but also to optimize testicular function.

Oswald et al in 2001 were the first to recommend the use of subdartos scrotal injection of isosulfan blue dye in order to reliably and objectively identify and spare the spermatic lymphatic vessels (7). In a comparative study this was found to be superior to the standard Palomo procedure (8). This encouraging experience with the open Palomo procedure was then applied to the laparoscopic Palomo procedure.

Podkamenev et al (9) in a randomized controlled trial compared laparoscopic varicocelectomy in children, performed in 434 patients, to open varicocelectomy, performed in 220 patients, both after injection of methylene blue under the tunica albuginea. They considered laparoscopic Palomo procedure with lymphatic sparing to be the most effective for varicocele treatment in children and adolescents. Furthermore, Schwentner et al (10) in a prospective randomized trial demonstrated no secondary hydrocele with the dye-assisted approach. Since then many studies have reported nearly zero rates of secondary hydrocele with dye-assisted LSLV $(11,12)$.

As a lymphatic staining agent the use of isosulfan 
blue is considered to be best $(7,10-12)$, because its use is well established in clinical practice and it is cheap. Tan et al (13) described the technique of in vivo methylene blue mapping of testicular lymphatic vessels during laparoscopic varicocelectomy. However, methylene blue dye can cause local complications such as skin and fat necrosis because of its tissue-reactive properties (14). We selected Indigo carmine as the lymphatic staining agents because it has been used to facilitate lymphatic mapping and the identification of sentinel nodes for staging in breast cancer and melanoma in Japan.

As to the injection space of dye, the techniques of subdartos or subcutaneous or intradartos scrotal injection of dye was reported. However, it seems that there was no difference in lymphatic vessel dyeing by the injection technique. We injected into the space between the tunica vaginalis and tunica albuginea using a 25 -gauge needle at ten minutes before the start of an operation and confirmed a good dyeing of the lymphatic vessels. If the stained lymphatics were not immediately seen after posterior peritoneotomy, the massage of a scrotum got a good dyeing of the lymphatics. However, it is important to be aware of the deleterious effects of intratesticular injection (15).

In this procedure, we raised the question of how many lymphatic vessels need to be spared, since other series report sparing from two to four visualized channels $(10,16,17)$. Capolicchio et al (12) described that they intentionally spared only one, since they noted that an additional lymphatic channel usually courses along the vas deferens. We also believed that it was important to spare one or two lymphatic channels to prevent a recurrence by the remnant of micro veins surrounding the lymphatics.

\section{CONCLUSION}

Dye-assisted LSLV in children is easily accomplished with excellent surgical outcome and sparing one or two lymphatics appears to be sufficient to avoid secondary hydrocele.

\section{CONFLICT OF INTEREST}

The author and co-authors disclose that there are no conflicts of interest associated with the present study.

\section{REFERENCES}

1. Dubin L, Amelar RD : Etiologic factors in 1294 consecutive cases of male infertility. Fertil Steril $22: 469-74,1971$

2. Akbay E, Cayan S, Doruk E, Duce MN, Bozlu $\mathrm{M}$ : The prevalence of varicocele and varicocelerelated testicular atrophy in Turkish children and adolescents. BJU Int 86 : 490-3, 2000

3. Stavropoulos NE, Mihailidis I, Hastazeris K, Moisidou R, Louka G, Filiadis I, Zouma E, Danella M, Kalomiris P : Varicocele in schoolboys. Arch Androl 48 : 187-92, 2002

4. Palomo A : Radical cure of varicocele by a new technique : preliminary report. J Urol 161 : 6049, 1949

5. Ivanissevich $\mathrm{O}$ : Left varicocele due to reflux ; experience with 4,470 operative cases in fortytwo years. J Int Coll Surg 34 : 742-55, 1960

6. Kocvara R, Dolezal J, Hampl R, Povýsil C, Dvorácek J, Hill M, Díte Z, Stanek Z, Novák K : Division of lymphatic vessels at varicocelectomy leads to testicular edema and decline in testicular function according to the LH-RH analogue stimulation test. Eur Urol 43 : 430-5, 2003

7. Oswald J, Korner I, Riccabona M : The use of isosulphan blue to identify lymphatic vessels in high retroperitoneal ligation of adolescent varicocele e avoiding postoperative hydrocele. BJU Int 87 : 502-4, 2001

8. Riccabona M, Oswald J, Koen M, Lusuardi L, Radmayr C, Bartsch G : Optimizing the operative treatment of boys with varicocele : sequential comparison of 4 techniques. J Urol 169 : 666-8, 2003

9. Podkamenev VV, Stalmakhovich VN, Urkov PS, Solovjev AA, Iljin VP : Laparoscopic surgery for pediatric varicoceles : randomized controlled trial. J Pediatr Surg 37(5) : 727-9, 2002

10. Schwentner C, Radmayr C, Lunacek A, Gozzi C, Pinggera GM, Neururer R : Laparoscopic varicocele ligation in children and adolescents using isosulphan blue : a prospective randomized trial. BJU Int 98 : 861-5, 2006

11. Tong Q, Zheng L, Tang S, Du Z, Wu Z, Mei $\mathrm{H}$, Ruan Q : Lymphatic sparing laparoscopic Palomo varicocelectomy for varicoceles in children : intermediate results. J Pediatr Surg 44 : 1509-13, 2009

12. Capolicchio JP, El-Sherbiny M, Brzezinski A, Eassa W, Jednak R : Dye-assisted lymphaticsparing laparoscopic varicocelectomy in children. 
J Pediatr Urol 9(1) : 33-7, 2013

13. Tan HL, Tecson B, Ee MZ, Tantoco J : Lymphatic sparing, laparoscopic varicocelectomy : a new surgical technique. Pediatr Surg Int 20 : 797-8, 2004

14. Borruto FA, Impellizzeri $\mathrm{P}$, Antonuccio $\mathrm{P}$, Finocchiaro A, Scalfari G, Arena F, Esposito C, Romeo C : Laparoscopic vs open varicocelectomy in children and adolescents : review of the recent literature and meta-analysis. J Pediatr Surg $45: 2464-9,2010$

15. Makari JH, Atalla MA, Belman AB, Rushton HG, Kumar S, Pohl HG : Safety and efficacy of intratesticular injection of vital dyes for lymphatic preservation during varicocelectomy. J Urol 178 : 1026-30, 2007

16. Golebiewski A, Krolak M, Komasara L, Czauderna P : Dye- assisted lymph vessels sparing laparoscopic varicocelectomy. J Laparoendosc Adv Surg Tech A 17 : 360-3, 2007

17. Chiarenza SF, D'Agostino S, Scarpa M, Fabbro M, Costa L, Musi L: Lymphography prior to laparoscopic Palomo varico- celectomy to prevent postoperative hydrocele. J Laparoendosc Adv Surg Tech A 16 : 394-6, 2006 